\title{
PENGARUH KOMBINASI BIOFILTER Glacilaria sp. DAN ZEOLIT TERHADAP LOGAM BERAT TIMBAL (Pb) PADA MEDIA AIR LAUT
}

\section{Effect of Combination of Glacilaria sp. and Zeolit Against Heavy Metal Concentration Lead (Pb) on Sea Water Media}

\author{
Akhmad Syafroni Affandi ${ }^{1 *}$, Boedi Setya Rahardja ${ }^{2}$ dan Hari Suprapto ${ }^{2}$. \\ ${ }^{1}$ Program Studi Budidaya Perairan, Fakultas Perikanan dan Kelautan, Universitas Airlangga, Surabaya \\ ${ }^{2}$ Departemen Manajemen Kesehatan Ikan dan Budidaya Perairan, Fakultas Perikanan dan Kelautan, Universitas \\ Airlangga, Surabaya \\ *akhmad-s-a-fpk10.web.unair.ac.id
}

\begin{abstract}
Abstrak
Logam berat yang terdapat di lingkungan dapat berbahaya bagi makhluk hidup. Logam berat yang sering mencemari lingkungan terutama adalah merkuri (Hg), timbal (Pb), arsenik (As), kadmium (Cd), khromium (Cr) dan nikel (Ni). Logam berat tersebut di dalam tubuh suatu individu dapat menggumpal dan tetap tinggal dalam tubuh dalam waktu yang lama sebagai racun yang terakumulasi. Dampak akut logam berat timbal atau plumbism dengan gejala utama meliputi kram perut, gagal ginjal, kemandulan hingga kerusakan otak permanen. Timbal juga merupakan faktor utama terjadinya gejala hiperaktif, penyimpangan tingkah laku dan kesulitan belajar pada anak - anak. Penelitian ini bertujuan untuk mengetahui pengaruh kombinasi Gracilaria sp. dan zeolit terhadap konsentrasi logam berat timbal $(\mathrm{Pb})$. Parameter utama pada penelitian ini adalah konsentrasi logam berat timbal, dan parameter pendukungnya adalah $\mathrm{pH}$, suhu, dan salinitas. Analisis data menggunakan ANOVA untuk melihat apakah terdapat perbedaan pada tiap perlakuan dan Uji Jarak Berganda Duncan untuk melihat perlakuan terbaik dalam penurunan konsentrasi logam berat timbal Berdasarkan hasil penelitian, diketahui bahwa kombinasi biofilter Gracilaria sp. dan zeolit berpengaruh sangat signifikan terhadap penurunan konsentrasi logam berat timbal $(\mathrm{p}<0,01)$. Kombinasi biofilter Gracilaria sp. dan zeolit memiliki pengaruh yang sangat signifikan terhadap penurunan konsentrasi Pb. Penurunan konsentrasi Pb oleh kombinasi biofilter Gracilaria sp. dan zeolit ini tercatat memiliki kisaran nilai 0,05 hingga 0,26 ppm. Perlakuan terbaik dalam menurunkan konsentrasi Pb tertinggi terdapat pada perlakuan P2-B (50 gram Glacilaria sp. dan 10 gram zeolit). Perlakuan ini mampu mengeliminasi konsentrasi $\mathrm{Pb}$ dalam media air sampai dengan rata rata $0,86 \%$ dalam waktu 28 hari.
\end{abstract}

Kata kunci: Glacilaria sp. dan Logam Berat Timbal

\begin{abstract}
Presence of heavy metals in the environment can be harmful to living things. Heavy metals are often pollute the environment mainly is mercury $(\mathrm{Hg})$, lead $(\mathrm{Pb})$, arsenic (As), cadmium (Cd), chromium $(\mathrm{Cr})$ and nickel (Ni). The heavy metal can clot in the body of an organism, and remains in the body for a long time as the toxins that have accumulated. Impact of acute lead or other heavy metals plumbism with major symptoms include abdominal cramps, kidney failure, sterility until permanent brain damage. Lead is also a major factor in the symptoms of hyperactivity, behavioral aberrations and learning difficulties in children - children. This study aims to determine the effect of the combination of Gracilaria sp . and zeolite to the concentration of heavy metals lead $(\mathrm{Pb})$. The main parameters in this study is the concentration of heavy metals lead and supporting parameters are $\mathrm{pH}$, temperature , and salinity . Data analysis using ANOVA to see whether there are differences in each treatment and Duncan's Multiple Range Test to see the best treatment in decreasing the concentration of heavy metals lead Based on this research, it is known that the combination of biofilter Gracilaria sp . and zeolites very significant influence on decreasing the concentration of heavy metals lead $(p<0.01)$. The combination of biofilter Gracilaria sp . and zeolites have a significant effect on decreasing the concentration $\mathrm{Pb}$. Reduction of $\mathrm{Pb}$ concentration by a combination of biofilter Gracilaria sp . and this zeolite has recorded a value range 0.05 to $0.26 \mathrm{ppm}$. The best treatment in reducing the $\mathrm{Pb}$ concentration is highest in treatment $\mathrm{P} 2$ - B (50 grams Glacilaria sp. And 10 grams of zeolite). This treatment is able to eliminate concentration of $\mathrm{Pb}$ in aqueous media up to an average within in 28 days.
\end{abstract}

Keywords: Glacilaria sp. and Heavy Metal 


\section{PENDAHULUAN}

Keberadaan logam berat di lingkungan dapat berbahaya bagi makhluk hidup. Logam berat yang sering mencemari lingkungan terutama adalah merkuri (Hg), timbal (Pb), kadmium (Cd), khromium (Cr) dan nikel (Ni). Logam berat tersebut dapat menggumpal di dalam tubuh suatu organisme, dan tetap tinggal dalam tubuh dalam waktu yang lama sebagai racun yang terakumulasi (Ghifari, 2011).

Menurut Yulianto dkk., (2006)

Gracilaria sp. diketahui memiliki kemampuan penyerapan logam berat yang tinggi karena memiliki dinding sel yang mengandung polisakarida. Hal ini juga didukung oleh hasil penelitian Nasuha dkk., (2014) diketahui bahwa Gracilaria sp. Memiliki efektifitas dalam menyerap logam berat timbal $(\mathrm{Pb})$ konsentrasi 0,09 ppm sebesar 0,337 ppm. Saktyo (2013) menyatakan penggunaan Gracilaria sp. sebagai biofilter mampu mengabsorbsi timbal $(\mathrm{Pb})$ konsentrasi 3 ppm sebesar 2,1221 ppm .

Adanya potensi yang dimiliki dari kedua bahan alam tersebut dapat dijadikan sebagai salah alternative dalam mengatasi pencemaran perairan (Pantjara dkk., 2010). Hal ini memungkinkan untuk dapat diaplikasikan pada kegiatan budidaya perairan laut dan payau (Komarawidjaja, 2003). Mengingat sifat logam berat timbal $(\mathrm{Pb})$ yang sangat berbahaya pada keadaan yang berlebihan, maka diperlukan suatu cara untuk mengurangi konsentrasi logam berat tersebut dalam perairan. Berdasarkan hal tersebut, perlu dilakukan penelitian mengenai kombinasi Gracilaria sp. Dan zeolit sebagai biofilter terhadap konsetrasi logam berat timbal $(\mathrm{Pb})$.

\section{METODOLOGI}

Waktu dan Tempat

Penelitian ini telah dilakukan di Laboratorium basah Pendidikan
Fakultas Perikanan dan Kelautan Universitas Airlangga Surabaya pada Bulan Agustus - November 2015.

\section{Materi Penelitian}

Peralatan Penelitian

Peralatan yang digunakan antara lain 20 unit akuarium dan masingmasing berukuran $40 \times 20 \times 25 \mathrm{~cm}^{3}$, pH meter, refraktometer, spektrofotometer, termometer, timbangan digital analitik, 1 buah blower, lima meter selang dan 64 buah batu aerasi.

Bahan Penelitian

Bahan yang digunakan pada penelitian ini adalah rumput laut Gracilaria sp. sebanyak 1000 gram dan berumur satu setengah bulan yang dibeli dari Petani Tambak Rumput Laut Gracilariasp. di kelurahan Medokan Ayu, Kecamatan Rungkut- Surabaya, 100 liter air laut, zeolit sebanyak 180 gram serta larutan standar logam berat timbal $(\mathrm{Pb})$.

\section{Metode Penelitian}

Penelitian ini menggunakan

Rancangan Acak Lengkap (RAL) dengan metode eksperimental yang terdiri dari 4 perlakuan dan 4 ulangan sehingga terdapat 16 unit percobaan.

Variabel dalam penelitian ini adalah sebagai berikut :

Variabel bebas : kombinasi biofilter Gracilaria sp. (50 gram) dan zeolit (5 gram, 10 gram, 15 gram dan 20 gram).

Variabel tergantung : konsentrasi logam berat timbal $(\mathrm{Pb})$ yaitu konsentrasi air laut awal tanpa penambahan $\mathrm{Pb}$ (kontrol) dan Pb 1 ppm.

\section{Prosedur Kerja}

Mula-mula disiapkan wadah berukuran 10 liter yang sudah bersih dan kering sebanyak 16 unit. Masing- 
masing wadah tersebut kemudian diisi dengan air laut sebanyak 5 liter dan di aerasi selama sehari penuh. Pada masing-masing unit percobaan diberikan Gracilaria sp. sebanyak 50 gram sedangkan zeolit diberikan sesuai dengan jumlah unit percobaan. Selanjutnya dilakukan aklimatisasi dengan melakukan penanaman selama 7 hari pencahayaan alami dan setiap 2 hari sekali dilakukan pergantian air.

Setelah dilakukan aklimatisasi, masing-masing unit percobaan siap untuk diaplikasikan dalam penelitian. Pada media tanam (air laut) P1, P2, P3 dan P4 unit percobaan diberi perlakuan berupa pemberian timbal $(\mathrm{Pb})$ sebanyak 1 ppm. Selanjutnya dilakukan pengamatan terhadap kualitas air dan pengukuran konsentrasi logam berat $\mathrm{Pb}$ pada masing-masing unit percobaan.

Pengamatan terhadap kualitas air dilakukan setiap hari pada pagi dan sore sedangkan pengukuran konsentrasi logam berat dilakukan sebelum penelitian (pada saat aklimatisasi), ssetelah aklimatisasi, minggu pertama dan kedua penelitian. Pengukuran konsentrasi logam berat $\mathrm{Pb}$ dilakukan dengan cara mengambil sampel media tanam berupa air laut pada tiap unit percobaan. Sampel yang telah didapat selanjunya dianalisis kandungan logam timbal $(\mathrm{Pb})$ dengan menggunakan AAS (Atomic Absorption Spectrophotometer) model AA-64015.

\section{Parameter Pengamatan}

Parameter utama yang diamati adalah konsentrasi logam timbal $(\mathrm{Pb})$ yang terdapat pada media tanam (air laut) dengan menggunakan uji Atomic Absorption Spectrophotometer (AAS) dan uji laboratorium.
Parameter pendukung penelitian ini adalah data kualitas air dalam akuarium yang meliputi salinitas, suhu dan $\mathrm{pH}$.

Analisa data berupa konsentrasi logam timbal $(\mathrm{Pb})$ dalam penelitian ini dilakukan dengan menggunakan Analisys of Variance (ANOVA) dan uji lanjut Duncan.

\section{Analisis Data}

Data yang diperoleh di analisis dengan uji satistik. Uji statistik yang digunakan adalah uji Anava dengan taraf 5\%. Uji Anava akan dilanjutkan dengan Uji Jarak Berganda Duncan untuk mengetahui tingkat perbedaan pada setiap perlakuan (Kusriningrum, 2012).

\section{HASIL DAN PEMBAHASAN \\ Hasil \\ Konsentrasi pada $\mathbf{P b}$}

Berdasarkan dari hasil penelitian yang telah dilakukan, konsentrasi $\mathrm{Pb}$ pada media air laut disajikan dalam grafik pada gambar 1. Grafik tersebut menunjukkan pengaruh perlakuan terhadap penurunan konsentrasi $\mathrm{Pb}$ pada media selama 4 minggu. Berdasarkan hasil pengujian dari tiap 2 minggu sekali, diketahui bahwa rata-rata penurunan konsentrasi tiap perlakuan memiliki kisaran antara 0,05 - 0,26 ppm. Perlakuan P2-B (kombinasi 50 gram Glacilaria sp. dan 10 gram zeolit) menunjukkan nilai penurunan konsentrasi $\mathrm{Pb}$ tertinggi. Hasil uji AAS pada pengaruh perlakuan terhadap penurunan konsentrasi Total $\mathrm{Pb}$ menunjukkan nilai signifikan yang lebih kecil dari 0,01. Ini menunjukkan bahwa terdapat perbedaan yang sangat siginifikan antara perlakuan P1-A sampai dengan P4-D. 


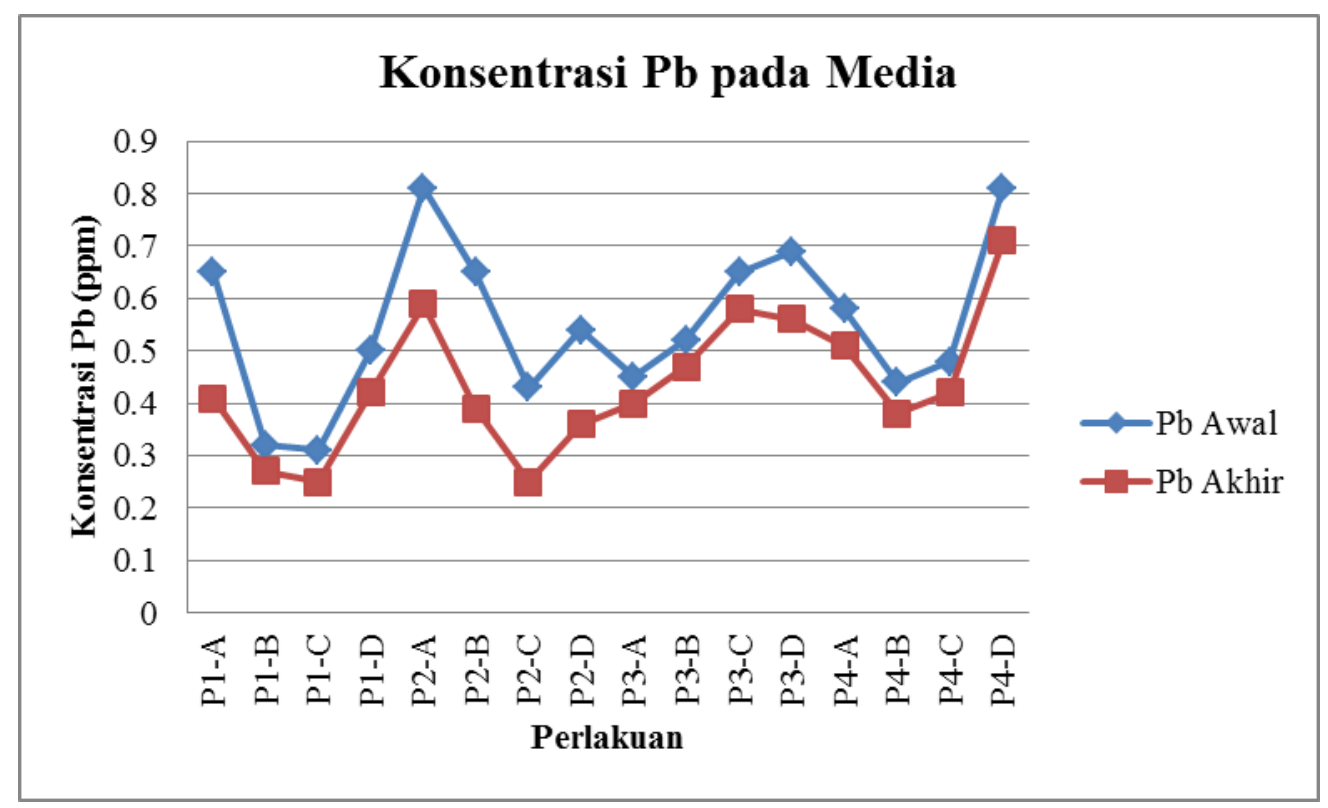

Gambar 1. Grafik Rata-rata Konsentrasi Pb pada air laut

Tabel 1. Konsentrasi logam berat Pb pada media air laut

\begin{tabular}{|c|c|c|c|c|c|}
\hline \multirow[b]{2}{*}{ Perlakuan } & \multicolumn{3}{|c|}{ Konsentrasi Pb (ppm) } & \multirow[b]{2}{*}{$\begin{array}{c}\text { Total } \\
\text { Penurunan }\end{array}$} & \multirow[b]{2}{*}{$\begin{array}{c}\text { Rata - } \\
\text { rata }\end{array}$} \\
\hline & $\begin{array}{c}\text { Po } \\
\text { (kontrol) }\end{array}$ & Pb Awal & $\begin{array}{c}\text { Pb } \\
\text { Akhir }\end{array}$ & & \\
\hline P1-A & 0,01 & 0.65 & 0.41 & 0,24 & \multirow{4}{*}{0,1075} \\
\hline P1-B & 0,01 & 0.32 & 0.27 & 0,05 & \\
\hline P1-C & 0,01 & 0.31 & 0.25 & 0,06 & \\
\hline P1-D & 0,01 & 0.50 & 0.42 & 0,08 & \\
\hline P2-A & 0,01 & 0.81 & 0.59 & 0,22 & \multirow{4}{*}{0,21} \\
\hline P2-B & 0,01 & 0.65 & 0.39 & 0,26 & \\
\hline $\mathrm{P} 2-\mathrm{C}$ & 0,01 & 0.43 & 0.25 & 0,18 & \\
\hline P2-D & 0,01 & 0.54 & 0.36 & 0,18 & \\
\hline P3-A & 0,01 & 0.45 & 0.40 & 0,05 & \multirow{4}{*}{0,3} \\
\hline P3-B & 0,01 & 0.52 & 0.47 & 0,05 & \\
\hline P3-C & 0,01 & 0.65 & 0.58 & 0,07 & \\
\hline P3-D & 0,01 & 0.69 & 0.56 & 0,13 & \\
\hline P4-A & 0,01 & 0.58 & 0.51 & 0,07 & \multirow{4}{*}{0,0725} \\
\hline P4-B & 0,01 & 0.44 & 0.38 & 0,06 & \\
\hline $\mathrm{P} 4-\mathrm{C}$ & 0,01 & 0.48 & 0.42 & 0,06 & \\
\hline P4-D & 0,01 & 0.81 & 0.71 & 0,10 & \\
\hline
\end{tabular}

Persentasi logam berat $\mathrm{Pb}$ pada Glacilaria $S p$

Gambar 2 menunjukkan persentase peningkatan konsentrasi $\mathrm{Pb}$ pada Gracilaria sp. yang digunakan sebagai biofilter. Berdasarkan hasil pengujian konsentrasi $\mathrm{Pb}$ tersebut, diketahui bahwa persentase $\mathrm{Pb}$ Glacilaria sp. pada perlakuan P1-A sampai dengan P4-D berkisar antara 0,27 - 0,86 \%. Rumput laut Glacilaria sp. pada perlakuan P2-B (kombinasi 50 gram dan zeolit 10 gram menunjukkan persentase peningkatan konsentrasi $\mathrm{Pb}$ yang tertinggi. 


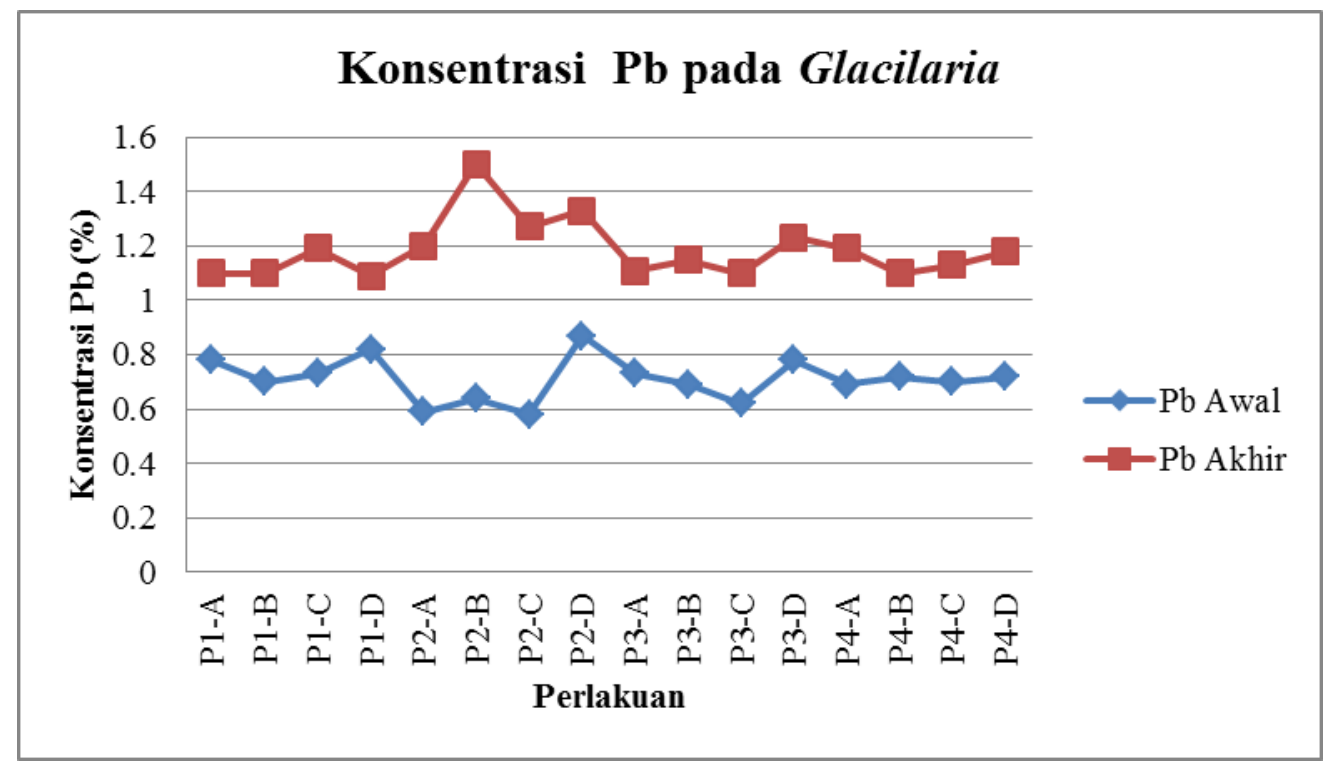

Gambar 2. Grafik Persentase Logam Berat Timbal Pb pada Glacilaria sp

\section{Kualitas air}

Kondisi kualitas air ( $\mathrm{pH}$ dan suhu) pada tiap perlakuan selama penelitian berlangsung. Berdasarkan pengukuran selama penelitian berlangsung, kisaran nilai ratarata $\mathrm{pH}$ berada pada rentang 9 . Sementara itu kisaran nilai rata - rata suhu air selama penelitian berada pada rentang $25-26^{\circ} \mathrm{C}$. Selain $\mathrm{pH}$ dan suhu, kualitas yang lainnya yang juga di ukur adalah salinitas. Nilai salinitas menunjukkan adanya peningkatan nilai, dari minggu pertama hingga minggu ke empat, yaitu 25 ppt.

\section{Pembahasan}

Berdasarkan data yang disajikan pada Tabel 1., dapat diinterpretasikan bahwa setiap kombinasi perlakuan terdapat perbedaan yang sangat signifikan terhadap penurunan konsentrasi Pb. Gambar 1. menunjukkan grafik penurunan konsentrasi $\mathrm{Pb}$ media pada kombinasi perlakuan yang diberikan.

Berdasarkan data yang disajikan pada Tabel 1., dapat diketahui bahwa penurunan konsentrasi $\mathrm{Pb}$ oleh perlakuan secara keseluruhan berkisar antara 0,05 - 0,26 ppm. Hal ini membuktikan bahwa perlakuan kombinasi biofilter Gracilaria sp. dan zeolit memiliki pengaruh yang sangat signifikan terhadap penurunan konsentrasi $\mathrm{Pb}$. Hasil uji AAS menunjukkan pengaruh sangat signifikan untuk penurunan konsentrasi $\mathrm{Pb}$ pada perlakuan. Demikian halnya dengan taraf perlakuan yang diberikan untuk faktor zeolit terhadap penurunan konsentrasi $\mathrm{Pb}$ juga menunjukkan pengaruh yang sangat signifikan.

Penurunan konsentrasi $\mathrm{Pb}$ tertinggi terdapat pada perlakuan P2-B (50 gram Glacilaria sp. dan 10 gram zeolit). Perlakuan ini mampu mengeliminasi konsentrasi $\mathrm{Pb}$ dalam media air sampai dengan 0,26 ppm dalam waktu 28 hari. Hal ini sesuai dengan penelitian Ihsan dkk, (2015) yang menunjukkan bahwa pemberian $\mathrm{Pb}$ pada awal penelitian dengan konsentrasi yang berbeda terhadap Glacilaria sp. memberikan pengaruh yang berbeda nyata terhadap penyerapannya.

Berdasarkan grafik interaksi antara faktor biofilter Gracilaria sp. dan zeolit dapat dinilai bahwa interaksi antar faktor memiliki interaksi yang positif searah, dalam artian bahwa interaksi antar faktor tersebut saling mendukung satu dengan yang lainnya. Hal ini ditunjukkan dengan saling menjauhinya garis respon. Hal ini sesuai dengan pendapat Kusriningrum 
(2010), bahwa interaksi positif searah ini adalah berupa beda besarnya respon yang terjadi apabila garis respon membuka saling menjauhi, atau taraf perlakuan lebih respon dari taraf kontrol.

Perlakuan terbaik dalam penurunan konsentrasi Total Pb berdasarkan uji AAS yang dilakukan pada perlakuan yang merupakan interaksi antar faktor dari perlakuan P1-A sampai dengan P4-D adalah P2-B yang berbeda sangat signifikan dengan perlakuan lain. Hal ini sesuai dengan pendapat Yudha (2009), bahwa semakin meningkat jumlah zeolit yang diberikan, maka semakin memperbesar jumlah poripori zeolit untuk menyerap Pb. Demikian halnya dengan biofilter Gracilaria sp.

Berdasarkan hasil pengujian konsentrasi $\mathrm{Pb}$, diketahui bahwa persentase peningkatan konsentrasi $\mathrm{Pb}$ pada Gracilaria sp. Pada Perlakuan P2-B sebesar 0,86\% membuktikan bahwa $\mathrm{Pb}$ diabsorpsi oleh Gracilaria sp. dan sesuai dengan Paulson (2014) yang menyatakan bahwa Gracilaria sp. merupakan alga yang paling efektif dalam proses bioremediasi laut karena memiliki kemampuan yang sangat tinggi dalam menyerap nutrisi. Menurut Pantjara dkk., (2010) rumput laut Gracilaria sp. mampu menyerap logam berat hingga $1.000 \mathrm{mg} / \mathrm{L}$.

\section{KESIMPULAN DAN SARAN Kesimpulan}

Kombinasi biofilter Gracilaria sp. dan zeolit memiliki pengaruh yang sangat signifikan terhadap penurunan konsentrasi $\mathrm{Pb}$. Penurunan konsentrasi Pb oleh kombinasi biofilter Gracilaria sp. dan zeolit ini tercatat memiliki kisaran nilai 0,05 hingga 0,26 ppm. Perlakuan terbaik dalam menurunkan konsentrasi $\mathrm{Pb}$ tertinggi terdapat pada perlakuan P2-B (50 gram Glacilaria sp. dan 10 gram zeolit). Perlakuan ini mampu mengeliminasi konsentrasi $\mathrm{Pb}$ dalam media air sampai dengan rata rata 0,86\% dalam waktu 28 hari.

\section{Saran}

Ditinjau dari hasil penelitian, maka disarankan untuk menggunakan kombinasi (50 gram Glacilaria sp. dan 10 gram zeolit). untuk memperoleh penurunan konsentrasi $\mathrm{Pb}$ yang terbaik. Selain itu, perlu dilakukan penelitian lebih lanjut tentang penggunaan biofilter Gracilaria sp. dan zeolit terhadap konsentrasi $\mathrm{Pb}$ pada sistem budidaya perairan.

\section{DAFTAR PUSTAKA}

Adnan, K., S. Badshah., C. Airoldi. 2011. Dithiocarbamated Chitosan as a Potent Biopolymer For Toxic Cation Remediation. Journal. Biointerfaces : Colloids and Surfaces : 3 (2) : 87-95.

Effendi, H. 2003. Telaah Kualitas Air Bagi Pengelolaan Sumber Daya dan Lingkungan Perairan. Penerbit Kanisius. Yogyakarta.

Firdaus, L. M. 2013. Studi Perbandingan Berbagai Adsorben Sintetis dan Alami Untuk Mengikat Logam Berat. Artikel Ilmiah. Progam Studi Pendidikan Kimia. Universitas Bengkulu. Bengkulu. Hal 1-7.

Ghifari, A. S. 2011. Heavy Metal Biopsortion in Aquatic Environment Using Rice (Oriza sativa L) Husks Waste as Biosorbent. Article. Pekan Kreativitas Mahasiswa. Universitas Indonesia. Hal 4-12.

Komarawidjaja, W dan D. A. Kurniawan. 2008. Tingkat Filtrasi Rumput Laut (Gracilaria sp.) Terhadap Kandungan Ortofosfat $\left(\mathrm{P}_{2} \mathrm{O}_{5}\right)$. Jurnal Tek-nologi Lingkungan 9 (2) : 180183.

Komarawidjaja, W. 2003. Peluang Pemanfaatan Rumput Laut Sebagai Agen Biofiltrasi Pada Ekosistem Perairan Payau Yang Tercemar. Jurnal. Teknologi Lingkungan 4 (3) : 155-159.

Lobban, C. S and P. J. Harrison. 1994. Seaweed Ecology and Physiology. New York. Cambridge University Press. Pp 234-237. 
Marine Algae of New Zealand. 2013. Taxonomy of Gracilaria sp. http:www.marinealgae.com. Diakses tanggal 27 Januari 2015.

Nasuha, T., Yuliani dan N. K. Indah. 2014. Efektifitas Gracilaria gigas Sebagai Biofilter Logam Berat Timbal (Pb) pada Media Tanam. Jurnal Lentera Bio 3 (1) : 91-96.

Ningrum, P. Y. 2006. Kandungan Logam Berat Timbal $(\mathrm{Pb})$ Serta Struktur Mikroanatomi Branchia Hepar dan Musculus Ikan Belanak (Mugil chepalus) di Perairan Cilacap. Skripsi. Jurusan Biologi. Fakultas Matematika dan Ilmu Pengetahuan Alam. Universitas Sebelas Maret. Surakarta. Hal 19-21.

Oktavia, D. A., D. Mangunwidjaja., S. Wibowo., T. C. Sunarti dan M. Rahayuningsih. 2012. Pengolahan Limbah Cair Perikanan Menggunakan Konsorsium Mikroba Indigenous Proteolitik dan Lipolitik. Jurnal Agrointek 6 (2) : 65-71.

Pantjara, B., Tahe., S. Mustofa dan E.A. Hendrajat. 2008. Pemanfaatan Tambak Marginal Tanah Sulfat Masam Untuk Budidaya Bandeng (Chanos-chanos), Nila Merah (Oreochromis niloticus) dan rumput laut (Gracilaria verucosa). Prosiding. Aquaculture Indonesia. Hal 295-302

Pantjara, B., E. A. Hendrajat dan H. S. Suwoyo. 2010. Pemanfaatan Biofilter pada Budidaya Udang Windu di Tambak Marjinal. Prosiding. Forum Inovasi Teknologi Akuakultur. Hal 221-231.

Palar, H. 2004. Pencemaran dan Toksikologi Logam Berat. Jakarta : Rieneka Cipta. Hal 35-37

Parawita, D., Insafitri dan W. A. Nugraha. 2009. Analisis Konsentrasi Logam Berat Timbal $(\mathrm{Pb})$ di Muara Sungai Porong. Jurnal Ilmu Kelautan 2 (2) : $34-42$.

Puji, S. G., J. P. Susanto dan A. Suwarni. 2008. Pengolahan Leachaet Terce- mar Pb Sebagai Upaya Pencegahan Pencemaran Lingkungan TPA. Jurnal Penelitian 8 (1) : 92-97.

Pramesti, R dan Nirwani. 2007. Studi Organ Reproduksi Gracilaria gigas Harvey pada Fase Karposporofit. Jurnal. Ilmu Kelautan 12 (2) : 9396.

Saktyo. A. H. 2013. Efek Timbal (Pb) dan Biofilter Rumput Laut (Gracilaria sp.) pada Teripang (Holothuroidea sp.) Sripsi. Progam Studi Budidaya Perairan. Fakultas Perikanan dan Kelautan. Universitas Airlangga. Surabaya. Hal 1-4.

Saputra, R. 2006. Pemanfaatan Zeolit Sintetis Sebagai Alternatif Pengolahan Limbah Industri. Artikel Ilmiah. Hal 1-8.

Sarjono, A. 2009. Analisis Kandungan Logam Berat $\mathrm{Cd}, \mathrm{Pb}$ dan $\mathrm{Hg}$ pada Air dan Sedimen di Perairan Kamal Muara Jakarta Utara. Skripsi. Departemen Manajemen Sumberdaya Perairan. Fakultas Perikanan dan Ilmu Kelautan. Institut Pertanian Bogor. Bogor. Hal 14.

Sofia. 2005. Metal Contamination in Commercially Important Fish and Shrimp Species collected From Aceh (Indonesia), Penang and Perak (Malaysia). Thesis. Universiti Sains Malaysia. Pp 12-14.

Suganal, 1989. Penggunaan Zeolit Bayah Untuk Pengolahan Air Limbah Industri Elektroplating di DKI Jakarta. Direktorat Jenderal Pertambangan Umum. Pusat Pengembangan Teknologi Mineral (PPTM), Bandung.

Sutopo., F.X.R. 1991. Pengkajian Karakteristik Zeolit Cikalong Tasikmalaya dan Pengolahannya dalam Pengolahan Air. Laporan. Teknik Pengolahan no. 143 PPTM. Bandung.

Trijayanti, R. 2010. Pengaruh Timbal (Pb) pada Udara Jalan Tol Terhadap Gambaran Mikroskopis Hepar dan Kadar Timbal $(\mathrm{Pb})$ dalam Darah 
Mencit BALB/C Jantan. Artikel Ilmiah. Pendidikan Sarjana Kedokteran. Fakultas Kedokteran. Universitas Diponegoro. Semarang. Hal 1-14.

Trisunaryati, W. 2009. Zeolit Alam Indonesia Sebagai Absorben dan Katalis dalam Mengatasi Masalah Lingkungan dan Krisis Energi. Pidato. Pengukungan Guru Besar Ilmu Kimia. Fakultas Matematika dan Ilmu Pengetahuan Alam. Universitas Gajah Mada. Yogyakarta. Hal 1-2.

Widodo. 2012. Pemanfaatan Zeolit Sebagai penyerap $\mathrm{Hg}$ dari Air Sungai Citambal Kecamatan Cineam Kabupaten Tasikmalaya yang Tercemar Pengolahan Emas dengan Metode Amalgasi. Buletin. Geologi Tata Lingkungan 22 (3) : $155-168$.

Yamamoto, H. 1978. Systematic and Anatomical Study of the Genus Gracilaria in Japan. Journal of Mem. Fac. Fish. Hokkaido University 25 (2) : 98-138.

Yulianto, B., R. Ariodan A. Triono. 2006. Daya Serap Rumput Laut (Gracilaria sp.) terhadap Logam Berat Tembaga (Cu) Sebagai Biofilter. Jurnal. Ilmu Kelautan 11 (2) : 72- 78 . 